\title{
PHOTODISSOCIATION SPECTROSCOPY OF $\left(\mathrm{C}_{6} \mathrm{H}_{6}\right)_{2}^{+}$
}

\author{
KAZUHIKO OHASHI, YASUHIRO NAKAI, TAKESHI SHIBATA and \\ NOBUYUKI NISHI \\ Department of Chemistry, Faculty of Science, Kyushu University, Hakozaki, \\ Fukuoka 812, Japan
}

(Received March 18, 1993)

\begin{abstract}
The photodissociation spectrum of $\left(\mathrm{C}_{6} \mathrm{H}_{6}\right)_{2}^{+}$is obtained from the yields of fragment $\mathrm{C}_{6} \mathrm{H}_{6}^{+}$ion as a function of photodissociation wavelength in the $400-1400 \mathrm{~nm}$ region. Two bands at 440 and $580 \mathrm{~nm}$ are attributed to the $\mathrm{C} \leftarrow \mathrm{X}$ and the $\mathrm{B} \leftarrow \mathrm{X}$ local excitation (LE) bands, respectively. Both the most intense band at $920 \mathrm{~nm}$ and relatively weak one at $1160 \mathrm{~nm}$ are assigned to charge resonance (CR) bands. The red-shift of the $\mathrm{B} \leftarrow \mathrm{X}$ band from that of $\mathrm{C}_{6} \mathrm{H}_{6}^{+}$and the cross sections at the $\mathrm{CR}$ bands much larger than those at the LE bands are consistent with a sandwich structure for $\left(\mathrm{C}_{6} \mathrm{H}_{6}\right)_{2}^{+}$. The appearance of the two CR bands is explained on the basis of displaced sandwich structures for $\left(\mathrm{C}_{6} \mathrm{H}_{6}\right)_{2}^{+}$.
\end{abstract}

KEY WORDS: photodissociation spectroscopy, benzene, cluster ion, charge resonance absorption

\section{INTRODUCTION}

New information on the structure and dynamics of cluster ions is now emerging from ion photodissociation studies. The photodissociation of size-selected cluster ions is the most common approach in cluster ion spectroscopy, because direct absorption or laser induced fluorescence experiments are accompanied with difficulty in preparing sufficient number densities of selected cluster ions. The photodissociation spectroscopy employs tandem mass filter arrangements that isolate cluster ions of specific size for photodissociation, and analyze the mass number of the resultant photofragments. Several cluster ions of atoms and small molecules have been probed by this method, and information about electronically excited states and the interaction between a chromophore and its environment has been obtained. ${ }^{1}$

Benzene dimer cation is the simplest prototype system in which the interaction between two aromatic molecules can be studied. Spectroscopic investigation on $\left(\mathrm{C}_{6} \mathrm{H}_{6}\right)_{2}^{+}$had been limited to the measurement of the absorption spectra in condensed phases before the advent of the photodissociation spectroscopy. The absorption 
spectra of $\mathrm{C}_{6} \mathrm{H}_{6}^{+}$and $\left(\mathrm{C}_{6} \mathrm{H}_{6}\right)_{2}^{+}$in the visible and near-infrared region were observed by $\gamma$-ray irradiation in glassy solutions ${ }^{2,3}$ and in low temperature matrices., ${ }^{4,5}$ An absorption band centered near $900 \mathrm{~nm}$ and another one at around $450 \mathrm{~nm}$ were assigned to $\left(\mathrm{C}_{6} \mathrm{H}_{6}\right)_{2}^{+}$. In the condensed phase measurement, absorption bands of different species may overlap in the spectra. Thus, there may be some ambiguity in identifying the species responsible for the photoabsorption. The photodissociation spectroscopy of size-selected cluster ions in the gas phase has advantages in that the size of the parent ions can easily be specified prior to photodissociation and unwanted solvent perturbations can be eliminated.

Based on the similarity of the absorption spectrum of $\left(\mathrm{C}_{6} \mathrm{H}_{6}\right)_{2}^{+}$to that of paracyclophane cation, most of the condensed-phase studies suggest or suppose a symmetrical sandwich structure for $\left(\mathrm{C}_{6} \mathrm{H}_{6}\right)_{2}^{+}$. Milosevich et al. reported the results of ab initio molecular orbital (MO) calculations for $\left(\mathrm{C}_{6} \mathrm{H}_{6}\right)_{2}^{+}$, where the benzene rings were assumed to lie one above the other in parallel planes. ${ }^{6}$ They found that all structures which allow $\pi$ overlap between parallel rings are bound. Recently, Yamabe et al. determined the structure of $\left(\mathrm{C}_{6} \mathrm{H}_{6}\right)_{2}^{+}$by ab initio spin-restricted openshell MO calculations. ${ }^{7}$ Two isomers, axial (T-shape) and parallel ones, were calculated to be located at the potential-energy minima.

In this article we describe the results of photodissociation spectroscopy of $\left(\mathrm{C}_{6} \mathrm{H}_{6}\right)_{2}^{+}$in the $400-1400 \mathrm{~nm}$ wavelength region. The parent $\left(\mathrm{C}_{6} \mathrm{H}_{6}\right)_{2}^{+}$ion is created through resonance-enhanced 2-photon ionization (RE2PI) of the neutral clusters. Time-of-flight (TOF) method is then employed to selectively excite $\left(\mathrm{C}_{6} \mathrm{H}_{6}\right)_{2}^{+}$by adjusting the timing of the second laser excitation to the arrival time of $\left(\mathrm{C}_{6} \mathrm{H}_{6}\right)_{2}^{+}$. The relative photodissociation cross sections at a series of wavelengths are obtained by monitoring the appearance of the fragment $\mathrm{C}_{6} \mathrm{H}_{6}^{+}$ion following the photodissociation of $\left(\mathrm{C}_{6} \mathrm{H}_{6}\right)_{2}^{+}$. The photodissociation spectrum recorded in this manner is the convolution of the absorption spectrum of $\left(\mathrm{C}_{6} \mathrm{H}_{6}\right)_{2}^{+}$and the dissociation probability at each wavelength. If the dissociation probability is independent of the wavelengths, then the measurement of the photodissociation spectrum is equivalent to that of the photoabsorption spectrum. Possible structures of $\left(\mathrm{C}_{6} \mathrm{H}_{6}\right)_{2}^{+}$are discussed on the basis of the observed photodissociation spectrum.

\section{EXPERIMENTAL}

The experiment was carried out by using a cluster beam apparatus with a reflectrontype time-of-flight (TOF) mass spectrometer (Jordan Co. Angular Reflectron). Schematic illustration of the apparatus is shown in Figure 1. Neutral benzene clusters were formed by expanding the mixture of benzene and argon through a pulsed valve (General Valve Series 9) with a 0.80 -mm orifice diameter and a $200-\mu$ s pulse duration. The total stagnation pressure was $\approx 1000$ Torr $(1 \mathrm{Torr} \approx 133 \mathrm{~Pa})$. After passing through a skimmer (1.0-mm diameter) and a collimator, the cluster beam entered the acceleration region of an ion source. Between the two acceleration grids, the 
cluster beam was crossed by a pulsed ionization laser $\left(\nu_{\mathrm{i}}=210 \mathrm{~nm}\right)$, where the parent ions were produced by RE2PI of the neutral clusters. While traveling in the acceleration region, the prepared ions were excited by a pulsed dissociation laser $\left(v_{\mathrm{d}}\right.$ $=400-1400 \mathrm{~nm}$ ) at 4-6 mm downstream from the ionization laser. The ion bunch of $\left(\mathrm{C}_{6} \mathrm{H}_{6}\right)_{2}^{+}$was selectively excited by adjusting the delay time between $v_{\mathrm{i}}$ and $\nu_{\mathrm{d}}$. This delay time was varied using a digital delay pulse generator (Stanford Research Systems DG-535), which also controlled the opening of the molecular beam valve. After secondary acceleration up to $\approx 2.5 \mathrm{kV}$, both the remaining parent ions and the photofragment ions were introduced into an ion-drift chamber of the mass spectrometer. After drifting through a field-free region of $1.07 \mathrm{~m}$, the ions were reflected by a two-stage ion reflector situated at the end of the mass spectrometer. The reflected ions traveled through another field-free region of $0.60 \mathrm{~m}$ and were detected by dual microchannel plates (Galileo 3320). Ion signals were amplified by a fast preamplifier (Anritsu $\mathrm{MH}-648 \mathrm{~A}$ ) and fed into a digital storage oscilloscope (LeCroy 9400).

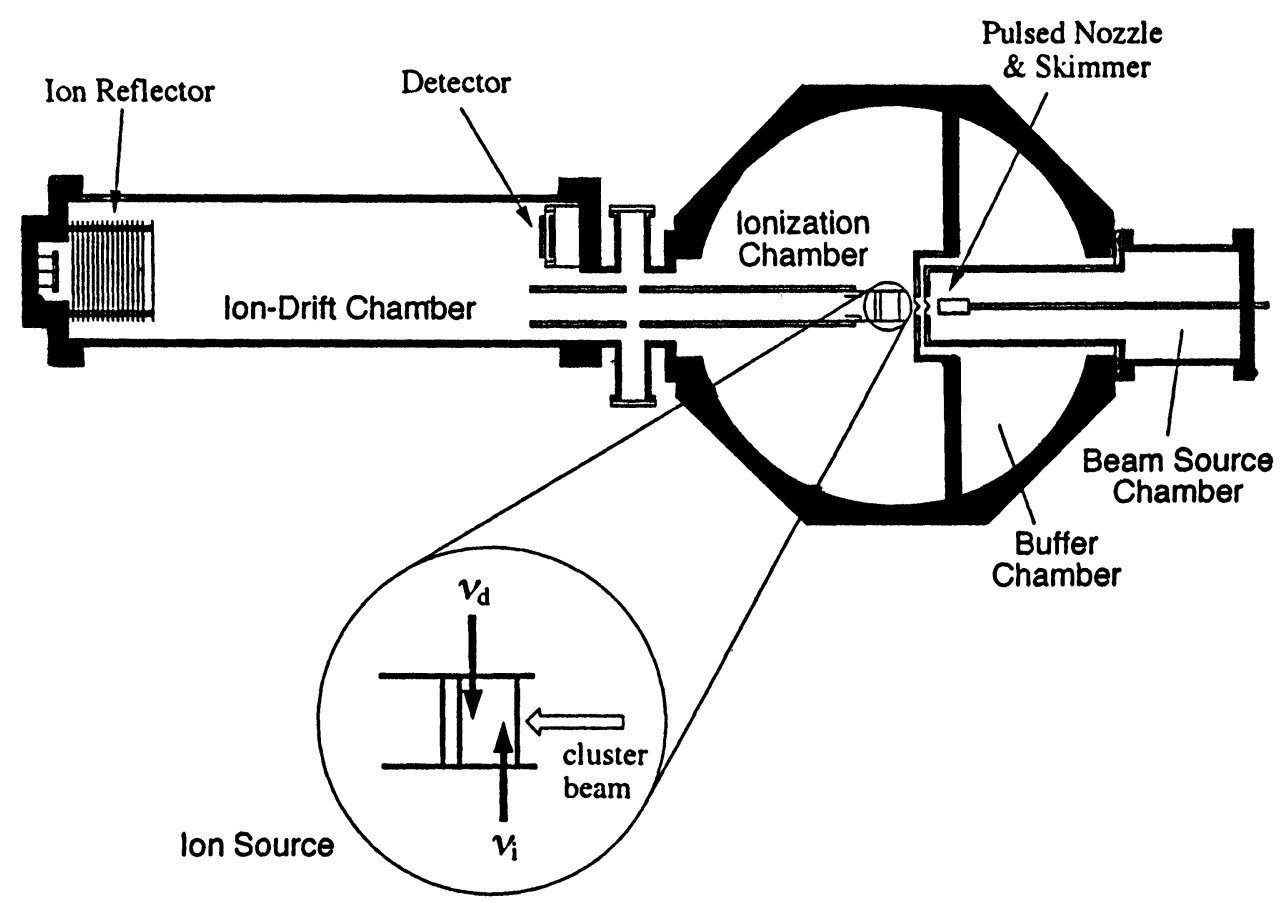

Figure 1 Schematic illustration of the cluster beam apparatus with the reflectron-type time-of-flight mass spectrometer. The apparatus consists of four chambers; molecular beam source, buffer, ionization, and ion-drift chamber. The ionization laser $\left(\nu_{\mathrm{i}}\right)$ and the photodissociation laser $\left(\nu_{\mathrm{d}}\right)$ are introduced into the ion source of the mass spectrometer, as indicated in the expanded view.

RE2PI for the ion preparation was achieved by pumping a dye laser (Lumonics HyperDYE-300) with a XeCl excimer laser (Lumonics TE-861) and by frequencydoubling the output with a $\mathrm{BBO}\left(\beta-\mathrm{Ba}_{2} \mathrm{~B}_{2} \mathrm{O}_{4}\right)$ crystal mounted in an autotracker 
(Lumonics HyperTRAK-1000). The fundamental output from a dye laser (Lumonics HyperDYE-300) pumped with a $\mathrm{XeCl}$ excimer laser (Lumonics HyperEX-400) was utilized for the photodissociation in the visible region. The output from a dye laser (Spectra-Physics PDL-3) pumped with a Nd:YAG laser (Spectra-Physics GCR-18S) was frequency-shifted through a Raman shifter (Spectra-Physics RS-1) and the first or the second Stokes line was used for the photodissociation in the near-infrared (IR) region. The intensities of the lasers were monitored by PIN photodiodes (Hamamatsu S1722-02) or an InGaAs photodiode (Hamamatsu G3476-05) and integrated by two boxcar averagers (Stanford Research Systems SR250) for the correction of laser power fluctuation and dye gain variation.

\section{RESULTS AND DISCUSSION}

\section{A. Parent Ion Preparation}

The direct absorption spectra of neutral benzene clusters in a free jet were measured in the 175-225 $\mathrm{nm}$ region by Hiraya and Shobatake. ${ }^{8}$ They found two broad absorption maxima at 208 and $185 \mathrm{~nm}$ and assigned to the $S_{2}$ and $S_{3}$ absorption systems of the clusters, respectively. The absorption cross sections in the $S_{2}$ region are much greater than those in the $S_{1}$ region. Following the excitation to the $S_{2}$ state the clusters form deeply bound excimers, and ionizing transitions from the excimer states are efficient in the RE2PI process. ${ }^{9}$ Thus RE2PI via the $S_{2}$ state $\left(v_{\mathrm{i}}=210 \mathrm{~nm}\right)$ is utilized to prepare $\left(\mathrm{C}_{6} \mathrm{H}_{6}\right)_{2}^{+}$. No information is available about the internal energy distributions of $\left(\mathrm{C}_{6} \mathrm{H}_{6}\right)_{2}^{+}$created by 1-color RE2PI of the neutral clusters via the $\mathrm{S}_{2}$ state. The 1-color RE2PI at $210 \mathrm{~nm}$ produces an excess energy of $\approx 3.3 \mathrm{eV}$ above the ionization threshold. The nascent hot cluster ions would release neutral molecules until the internal energy becomes low enough to retain the most weakly bound molecule. Hence the internal energy of $\left(\mathrm{C}_{6} \mathrm{H}_{6}\right)_{2}^{+}$at the time of exposure to the dissociation laser should not be so large as would be anticipated from the excess energy. The average internal energy of less than $0.1 \mathrm{eV}$ is estimated for $\left(\mathrm{C}_{6} \mathrm{H}_{6}\right)_{2}^{+}$by a statistical phase space calculation for the photodissociation process. ${ }^{10}$

\section{B. Photodissociation Spectrum}

Photodissociation spectroscopic experiments are performed to investigate the electronic and geometric structure of $\left(\mathrm{C}_{6} \mathrm{H}_{6}\right)_{2}^{+}$. In the wavelength range studied, the only energetically possible dissociation pathway of $\left(\mathrm{C}_{6} \mathrm{H}_{6}\right)_{2}^{+}$is the formation of $\mathrm{C}_{6} \mathrm{H}_{6}^{+}$and $\mathrm{C}_{6} \mathrm{H}_{6}$. The relative photodissociation cross sections at a series of wavelengths are obtained by monitoring the appearance of the photofragment $\mathrm{C}_{6} \mathrm{H}_{6}^{+}$ion following the photodissociation of $\left(\mathrm{C}_{6} \mathrm{H}_{6}\right)_{2}^{+}$. Figure 2 shows the photodissociation spectrum for $\left(\mathrm{C}_{6} \mathrm{H}_{6}\right)_{2}^{+}$. The spectrum is recorded at intervals of $2-5 \mathrm{~nm}$ from overlapping dye laser scans. In the $400-970 \mathrm{~nm}$ region the fundamental output of the excimer-pumped dye laser is used. The first and the second Stokes lines 
from the Raman-shifter are employed in the $830-1030 \mathrm{~nm}$ and the $1000-1400 \mathrm{~nm}$ regions, respectively. During the measurement, the power of the dissociation laser is carefully controlled to ensure that the photodissociation process remains in the linear region. The fragment ion intensities are normalized according to the dissociation laser power recorded simultaneously. The measurement performed with a given dye is scaled to the others based on cross sections determined in overlapping regions of the dye gain curves. The error bars indicate one standard deviation of statistical uncertainties determined from repeated dye laser scans. In principle, if the dissociation probability is independent of the wavelengths, then the measurement of the photodissociation spectrum is equivalent to that of the photoabsorption spectrum. The photodissociation quantum yield of $\left(\mathrm{C}_{6} \mathrm{H}_{6}\right)_{2}^{+}$is found to be near unity in the wavelength range studied here. Thus the photodissociation spectrum can be directly related to the photoabsorption spectrum of $\left(\mathrm{C}_{6} \mathrm{H}_{6}\right)_{2}^{+}$.

Traditionally, $\left(\mathrm{C}_{6} \mathrm{H}_{6}\right)_{2}^{+}$was studied by the direct absorption spectroscopy in the condensed phases. ${ }^{2-5} \mathrm{~A}$ broad band centered around $900 \mathrm{~nm}$ and another one at $450 \mathrm{~nm}$ were assigned to $\left(\mathrm{C}_{6} \mathrm{H}_{6}\right)_{2}^{+}$. The former band was attributed to an intervalence transition band, or in other words, a charge resonance (CR) band. This is a characteristic band of $\left(\mathrm{C}_{6} \mathrm{H}_{6}\right)_{2}^{+}$which is due to an electronic transition between two $\mathrm{CR}$ states correlated to $\mathrm{C}_{6} \mathrm{H}_{6}^{+}(\mathrm{X})+\mathrm{C}_{6} \mathrm{H}_{6}(\mathrm{X})$. The latter band was attributed to a local excitation (LE) band, in which an electronic transition of a monomer cation unit within $\left(\mathrm{C}_{6} \mathrm{H}_{6}\right)_{2}^{+}$is locally excited.

Photoelectron spectroscopic studies provide useful information on the energies of several electronic states of $\mathrm{C}_{6} \mathrm{H}_{6}^{+}$. The adiabatic ionization energies were found to be $9.241 \mathrm{eV}$ for $\mathrm{X}\left(\mathrm{E}_{1 \mathrm{~g}}\right)$ state, $11.488 \mathrm{eV}$ for $\mathrm{B}\left(\mathrm{E}_{2 \mathrm{~g}}\right)$ state, and $12.3 \mathrm{eV}$ for $\mathrm{C}\left(\mathrm{A}_{2 \mathrm{u}}\right)$ state. ${ }^{11}$ Thus the $\mathrm{C} \leftarrow \mathrm{X}$ and the $\mathrm{B} \leftarrow \mathrm{X}$ transitions of $\mathrm{C}_{6} \mathrm{H}_{6}^{+}$are expected around 3.1 and $2.25 \mathrm{eV}$, respectively. The $\mathrm{C} \leftarrow \mathrm{X}$ transition is due to the promotion of an electron from the lowest occupied $\pi$ orbital $\left(a_{2 u}\right)$ to the singly occupied $\pi$ orbital $\left(e_{1 g}\right)$, and it is dipole allowed. On the other hand, the $\mathrm{B} \leftarrow \mathrm{X}$ transition corresponds to the excitation of an electron from the inner $\sigma$ orbital $\left(\mathrm{e}_{2 \mathrm{~g}}\right)$ to the $\pi$ orbital $\left(\mathrm{e}_{1 \mathrm{~g}}\right)$, and this is a dipole forbidden transition in $\mathrm{D}_{6 \mathrm{~h}}$ symmetry. One can assign the $440-\mathrm{nm}$ $(2.82 \mathrm{eV})$ and the $580-\mathrm{nm}(2.14 \mathrm{eV})$ bands in the photodissociation spectrum of $\left(\mathrm{C}_{6} \mathrm{H}_{6}\right)_{2}^{+}$to the $\mathrm{LE}$ bands of the $\mathrm{C} \leftarrow \mathrm{X}$ and the $\mathrm{B} \leftarrow \mathrm{X}$ transitions, respectively. ${ }^{12}$ The $B \leftarrow X$ transition is expected to get intensity in $\left(\mathrm{C}_{6} \mathrm{H}_{6}\right)_{2}^{+}$because of intermolecular motions between the two benzene units and its intensity can be enhanced when these motions are coupled with out-of-plane intramolecular vibrations of the monomer units. Another important factor is the vibronic mixing between the B state and the nearest repulsive $C R$ state. In fact, the intensity of the $B \leftarrow X$ transition of $\left(\mathrm{C}_{6} \mathrm{H}_{6}\right)_{2}^{+}$is fairly stronger than those of normal $\pi \leftarrow \sigma$ transitions of monomers and it could be elucidated by considering the mixing of the two states.

Walter et al. obtained a well-resolved spectrum of the $\mathrm{B} \leftarrow \mathrm{X}$ transition of $\mathrm{C}_{6} \mathrm{H}_{6}^{+}$and determined the origin as $18113 \mathrm{~cm}^{-1}$ (Reference 13). Although the origin of the $\mathrm{B} \leftarrow \mathrm{X}$ transition of $\left(\mathrm{C}_{6} \mathrm{H}_{6}\right)_{2}^{+}$is not clearly seen in Figure 2, the onset of the hump could be assigned at $600 \mathrm{~nm}$. This onset value gives a red-shift of 
$\approx 1400 \mathrm{~cm}^{-1}(\approx 0.18 \mathrm{eV})$, relative to that of $\mathrm{C}_{6} \mathrm{H}_{6}^{+}$, upon dimer formation. If $\left(\mathrm{C}_{6} \mathrm{H}_{6}\right)_{2}^{+}$ has a parallel sandwich structure, then the intermolecular (clustering) axis lies in the direction perpendicular to the plane of each benzene ring. In such a case, the $\pi$ orbitals are more likely to be stabilized than the $\sigma$ orbital upon clustering. The observed red-shift of the $\mathrm{B} \leftarrow \mathrm{X}$ band can be reasonably explained by the stabilization of the $\pi$ orbitals upon the parallel stacking.

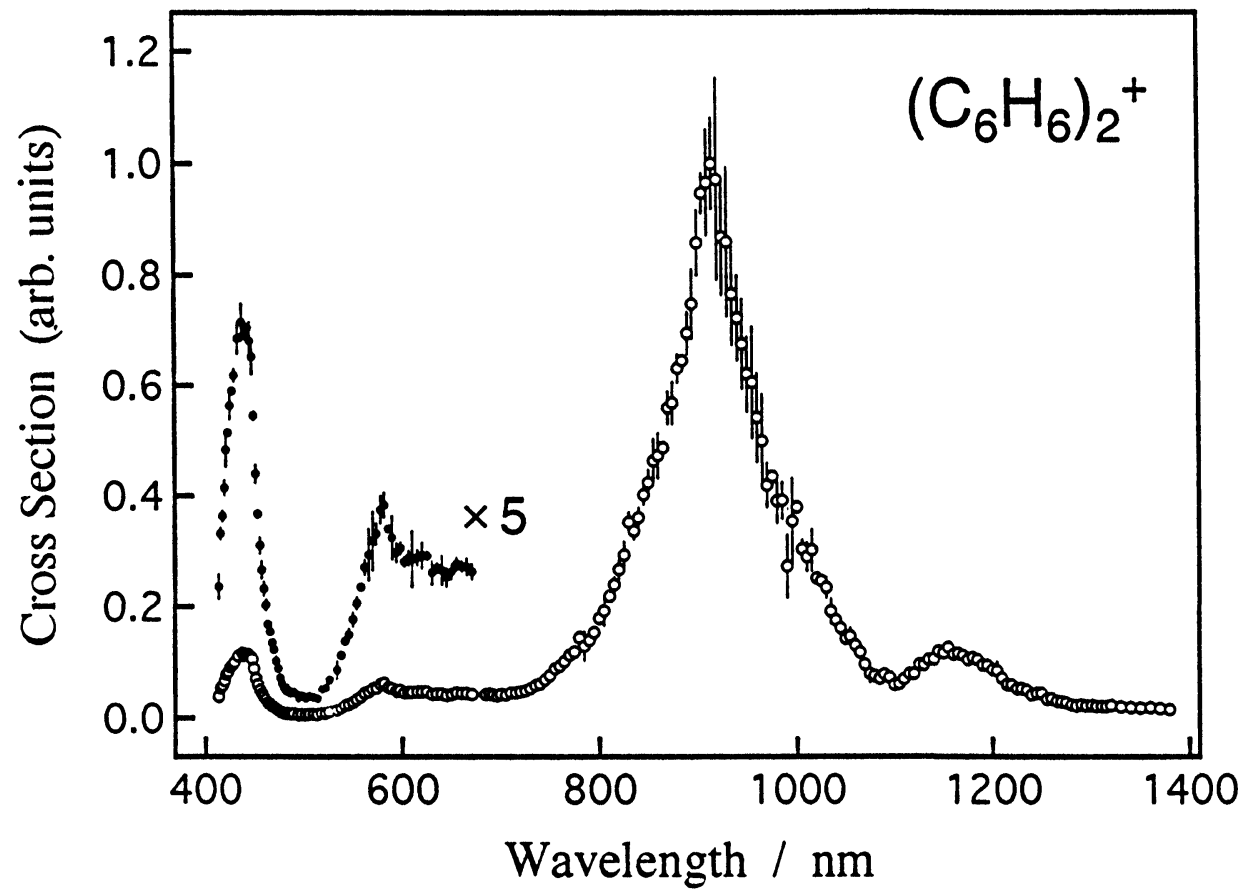

Figure 2 Photodissociation spectrum (plots of normalized yields of the fragment $\mathrm{C}_{6} \mathrm{H}_{6}^{+}$ion against the photodissociation wavelengths) of $\left(\mathrm{C}_{6} \mathrm{H}_{6}\right)_{2}^{+}$. The closed circles in the 410-670 nm region are magnification of the data by a factor of 5 . The error bars indicate one standard deviation of statistical uncertainties determined from repeated dye laser scans. It should be noted that the $580-\mathrm{nm}$ band is superimposed on the underlying broad tail of the $920-\mathrm{nm}$ band.

The 920-nm band is in agreement with the earlier condensed-phase assignment to a CR band of $\left(\mathrm{C}_{6} \mathrm{H}_{6}\right)_{2}^{+}$(Reference 14). The CR band is due to the transition from the ground state to the dissociative excited state of $\left(\mathrm{C}_{6} \mathrm{H}_{6}\right)_{2}^{+}$formed by in-phase and out-of-phase combination of the wave functions, ${ }^{15}$

$$
\begin{aligned}
& \psi_{+}=(2+2 S)^{-1 / 2}\left(\Psi_{1}^{+} \psi_{2}+\psi_{1} \psi_{2}^{+}\right) \\
& \psi_{-}=(2-2 S)^{-1 / 2}\left(\psi_{1}^{+} \psi_{2}-\psi_{1} \psi_{2}^{+}\right),
\end{aligned}
$$

respectively, where $\psi_{\mathrm{i}}^{+}$and $\psi_{\mathrm{i}}(\mathrm{i}=1,2)$ are the electronic wave functions of $\mathrm{C}_{6} \mathrm{H}_{6}^{+}(\mathrm{X})$ and $\mathrm{C}_{6} \mathrm{H}_{6}(\mathrm{X})$, respectively, and $\mathrm{S}=\left\langle\psi_{1}^{+} \psi_{2} \mid \psi_{1} \psi_{2}^{+}\right\rangle$. The absorption cross sections 
in the CR band are almost one order of magnitude larger than those in the LE bands. The existence of such an intense CR absorption suggests that the charge is shared with the two benzene molecules within $\left(\mathrm{C}_{6} \mathrm{H}_{6}\right)_{2}^{+}$in the ground state and that the two moieties should be equivalent to each other. The T-shape structure for $\left(\mathrm{C}_{6} \mathrm{H}_{6}\right)_{2}^{+}$ predicted by the $a b$ initio $\mathrm{MO}$ calculation ${ }^{7}$ is in conflict with the observation of the intense $\mathrm{CR}$ band.

The location of the CR bands revealed by the gas-phase photodissociation spectroscopy of several aromatic dimer ions is as follows: $920 \mathrm{~nm}$ for $\left(\mathrm{C}_{6} \mathrm{H}_{6}\right)_{2}^{+}, 1020 \mathrm{~nm}$ for $\left(\mathrm{C}_{6} \mathrm{H}_{5} \mathrm{CH}_{3}\right)_{2}^{+}$(Reference 16), and $1500 \mathrm{~nm}$ for $\left(\mathrm{p}-\mathrm{C}_{6} \mathrm{H}_{4} \mathrm{~F}_{2}\right)_{2}^{+}$(Reference 17). On the other hand, the binding energies $\left(\mathrm{E}_{0}\right)$ of these ions were determined by Ernstberger et al. from the measurement of the appearance potentials of metastable monomer evaporation and the ionization potentials of the neutral dimers. ${ }^{18}$ The transition energy between the two CR states $\left(\psi_{+}\right.$and $\left.\psi_{-}\right)$and the binding energy are given by ${ }^{15}$

$$
\begin{aligned}
\Delta \mathrm{E} & =2\left(\mathrm{SH}_{11}-\mathrm{H}_{12}\right) /\left(1-\mathrm{S}^{2}\right) ; \\
\mathrm{E}_{0} & =\left(\mathrm{SH}_{11}-\mathrm{H}_{12}\right) /(1+\mathrm{S}),
\end{aligned}
$$

respectively, where $\mathrm{H}_{11}=\left\langle\psi_{1}^{+} \psi_{2}|\mathrm{H}| \psi_{1}^{+} \psi_{2}\right\rangle$ and $\mathrm{H}_{12}=\left\langle\psi_{1}^{+} \psi_{2}|\mathrm{H}| \psi_{1} \psi_{2}^{+}\right\rangle$. From 2 Equations (2) and (3), one obtains the relation

$$
\mathrm{E}_{0}=(1-\mathrm{S}) \Delta \mathrm{E} / 2 \text {. }
$$

When the intermolecular overlap integral (S) is negligibly small, one can get the simple equation

$$
\mathrm{E}_{0}=\Delta \mathrm{E} / 2=\left|\mathrm{H}_{12}\right| \text {. }
$$

Equation (5) indicates that half the energy of the CR transition is equal to the binding energy of the dimer ion. Validity of this relation is confirmed in Figure 3, where half the transition energy $(\Delta \mathrm{E} / 2)$ is plotted against the binding energy $\left(\mathrm{E}_{0}\right)$. The magnitude of $(\Delta E / 2)$ is equivalent to $E_{0}$ within experimental errors. The result suggests that for the aromatic dimer ions the intermolecular overlap integral can be regarded to be negligibly small. In such a case, the binding energies can be estimated spectroscopically from the energies of the CR transitions.

The $1160-\mathrm{nm}$ band is assigned to another $\mathrm{CR}$ band of $\left(\mathrm{C}_{6} \mathrm{H}_{6}\right)_{2}^{+}$(Reference 19). The appearance of the two CR bands suggests that (i) there exist at least two isomers of $\left(\mathrm{C}_{6} \mathrm{H}_{6}\right)_{2}^{+}$; (ii) $\left(\mathrm{C}_{6} \mathrm{H}_{6}\right)_{2}^{+}$has a displaced sandwich structure where the two transitions are allowed. Most of the condensed-phase studies suggest or suppose that $\left(\mathrm{C}_{6} \mathrm{H}_{6}\right)_{2}^{+}$has a symmetrical sandwich structure which has $\mathrm{D}_{6 \mathrm{~h}}$ symmetry. The MO configuration of $\left(\mathrm{C}_{6} \mathrm{H}_{6}\right)_{2}^{+}$with $\mathrm{D}_{6 \mathrm{~h}}$ symmetry is $\left(\mathrm{e}_{1 \mathrm{u}}\right)^{4}\left(\mathrm{e}_{1 \mathrm{~g}}{ }^{*}\right)^{3}$, where $\mathrm{e}_{1 \mathrm{u}}\left(\mathrm{e}_{1 \mathrm{~g}}{ }^{*}\right)$ is the bonding (antibonding) combination of the doubly degenerate highest occupied molecular orbitals (HOMO's) of benzene. The HOMO's of benzene, $\pi_{x}$ and $\pi_{y}$, are schematically represented in Figure 4 (c). By the ab initio $\mathrm{MO}$ calculations for $\left(\mathrm{C}_{6} \mathrm{H}_{6}\right)_{2}^{+}$, Milosevich et al. showed that one benzene ring of each can slide freely for $\approx 0.04 \mathrm{~nm}$ to give displaced structures. In the displaced structures, bonding or antibonding with respect 


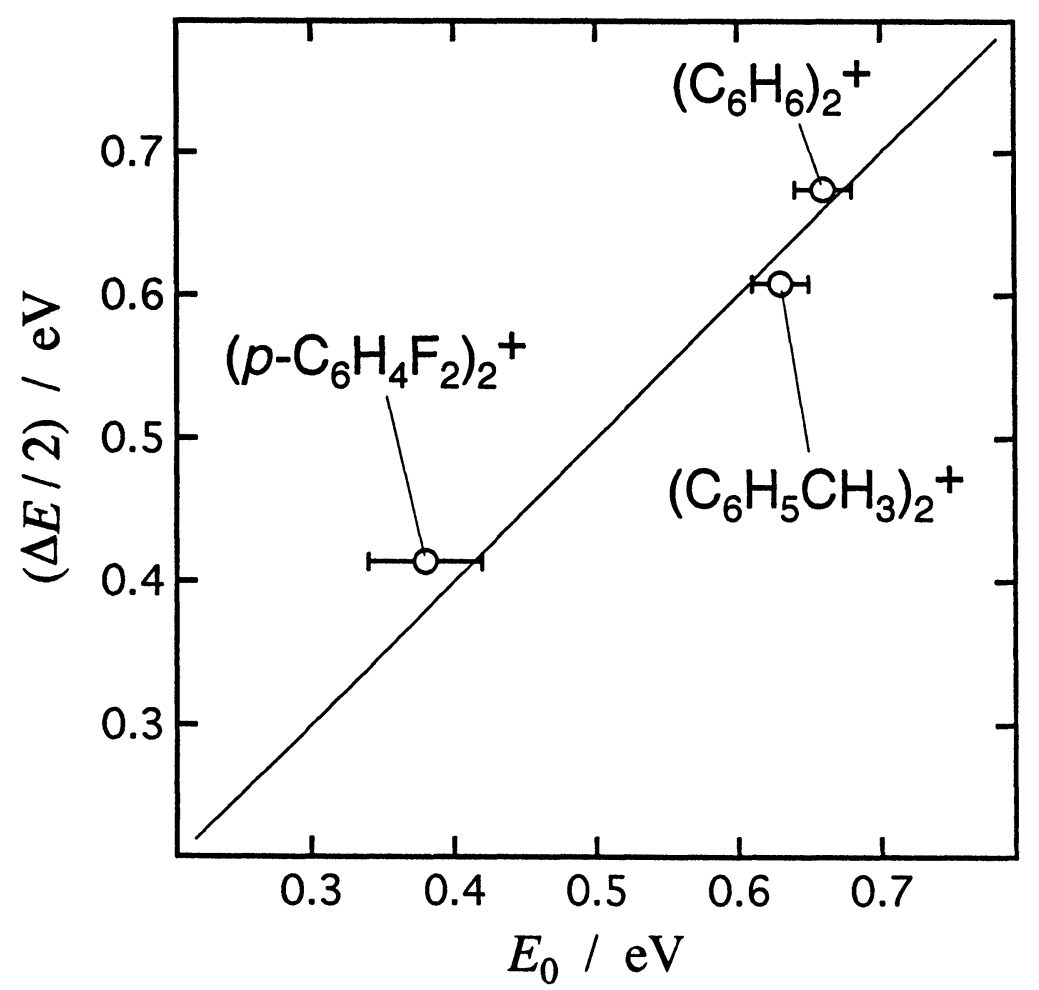

Figure 3 Comparison of the half the energy of the CR transition $(\Delta \mathrm{E} / 2)$ with the binding energy $\left(\mathrm{E}_{0}\right)$ for benzene, toluene, and $p$-difluorobenzene dimer ions. The solid line stands for the relation: $\Delta \mathrm{E} / 2=$ $\mathrm{E}_{0}$.

to the intermolecular coordinate lifts the degeneracy of the in-plane axes. The orbital energy diagram is schematically shown in Figure 4(a) for the structure where one benzene ring of each is slightly displaced along the $x$ axis with $C_{2 h}$ symmetry. The $\pi_{\mathrm{xu}}\left(=\pi_{\mathrm{x}}^{1}-\pi_{\mathrm{x}}^{2}\right)$ and the $\pi_{\mathrm{xg}}\left(=\pi_{\mathrm{x}}^{1}+\pi_{\mathrm{x}}^{2}\right)$ orbitals are either stabilized or unstabilized depending on the extent of the displacement, where the superscripts 1 and 2 denote the component benzene rings. When the displacement is small as shown in the figure, the MO configuration is $\left(\pi_{\mathrm{yu}}\right)^{2}\left(\pi_{\mathrm{xu}}\right)^{2}\left(\pi_{\mathrm{xg}} *\right)^{2}\left(\pi_{\mathrm{yg}} *\right)^{1}$. Here, two transitions, $\pi_{\mathrm{yg}}{ }^{*} \leftarrow \pi_{\mathrm{y}}$ and $\pi_{\mathrm{yg}}{ }^{*} \leftarrow \pi_{\mathrm{xu}}$, are group theoretically allowed in $\mathrm{C}_{2 \mathrm{~h}}$ symmetry. The $\pi_{\mathrm{yg}}{ }^{*} \leftarrow \pi_{\mathrm{yu}}$ transition has a dipole moment along the intermolecular axis and is strongly allowed. The $\pi_{\mathrm{yg}}{ }^{*} \leftarrow \pi_{\mathrm{xu}}$ transition has a dipole moment in the parallel planes and gets intensity only when the structure of the component molecules is distorted from $\mathrm{D}_{6 \mathrm{~h}}$ symmetry. One can assign the intense $920-\mathrm{nm}$ band to the $\pi_{\mathrm{yg}}{ }^{*} \leftarrow \pi_{\mathrm{yu}}$ transition and the relatively weak 1160-nm band to the $\pi_{\mathrm{yg}}{ }^{*} \leftarrow \pi_{\mathrm{xu}}$ transition. If the displacement is so large that there is little overlap between the benzene rings, the energy levels of the $\pi_{\mathrm{xu}}$ and the $\pi_{\mathrm{xg}}$ orbitals interchange. In this case only the $\pi_{\mathrm{yg}}{ }^{*} \leftarrow \pi_{\mathrm{yu}}$ transition would be observed in the near-IR region, because the $\pi_{\mathrm{yg}}{ }^{*} \leftarrow \pi_{\mathrm{xu}}{ }^{*}$ transition would appear in the mid-IR region. Figure 4 (b) gives the orbital energy diagram for the structure where one 


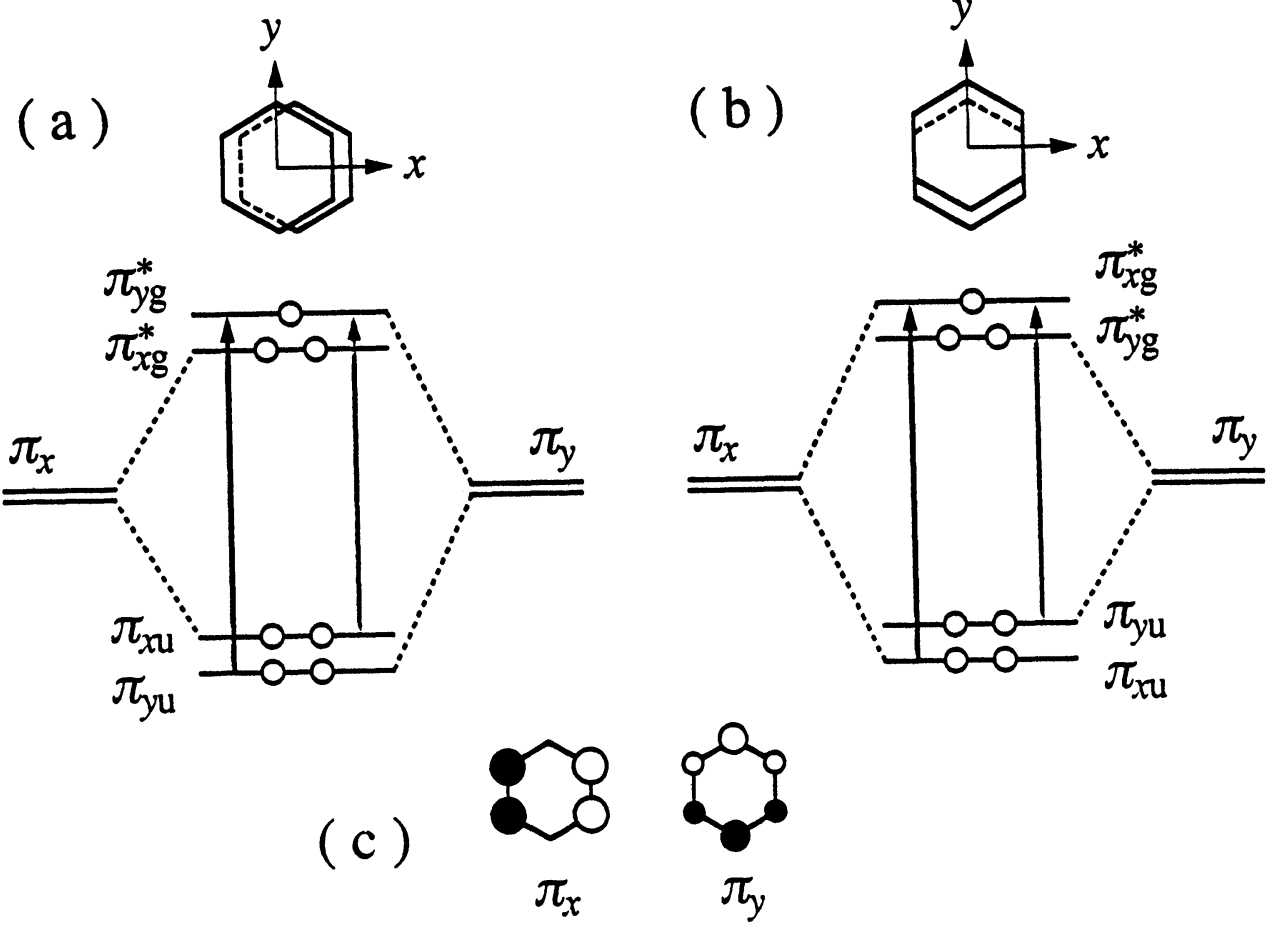

Figure 4 Orbital energy diagrams for $\left(\mathrm{C}_{6} \mathrm{H}_{6}\right)_{2}^{+}$with displaced parallel structures. (a) one benzene ring of each is slightly displaced along the $\mathrm{x}$ axis with $\mathrm{C}_{2 \mathrm{~h}}$ symmetry. (b) same as (a) but displaced along the $y$ axis. (c) schematic representation of the highest occupied molecular orbitals of benzene (not drawn to scale).

benzene ring of each is displaced along the y axis. The MO configuration is $\left(\pi_{\mathrm{xu}}\right)^{2}$ $\left(\pi_{\mathrm{yu}}\right)^{2}\left(\pi_{\mathrm{yg}} *\right)^{2}\left(\pi_{\mathrm{xg}}\right)^{1}$ for the slightly displaced structure. Here one can assign the 920-nm and the 1160-nm bands to the allowed $\pi_{\mathrm{xg}} * \leftarrow \pi_{\mathrm{xu}}$ and the $\pi_{\mathrm{xg}} * \leftarrow \pi_{\mathrm{yu}}$ transitions, respectively. When the displacement is large, the energy levels of the $\pi_{\mathrm{yu}}$ and the $\pi_{\mathrm{yg}}$ orbitals interchange and only the $\pi_{\mathrm{xg}}{ }^{*} \leftarrow \pi_{\mathrm{xu}}$ transition would be observed in the near-IR region. In either case (a) or (b), the appearance of the two CR band can be explained by considering a slightly displaced structure for $\left(\mathrm{C}_{6} \mathrm{H}_{6}\right)_{2}^{+}$. Further detailed discussion will be given elsewhere. ${ }^{20}$

\section{Photodissociation Mechanisms}

Figure 5 shows schematic potential energy curves for $\left(\mathrm{C}_{6} \mathrm{H}_{6}\right)_{2}^{+}$as a function of intermolecular distance. Energy levels for $\left(\mathrm{C}_{6} \mathrm{H}_{6}\right)_{2}^{+}$are determined from the photodissociation spectrum. Energies for asymptotic monomer levels are taken from Reference 11. For the photodissociation at the $\operatorname{LE}(\pi \pi)$ band, the energy disposal was found to agree very well with the prediction by the statistical phase space theory. ${ }^{10,21}$ As shown in Figure 5, the $\operatorname{LE}(\pi \pi)$ state of $\left(\mathrm{C}_{6} \mathrm{H}_{6}\right)_{2}^{+}$is bound relative to 


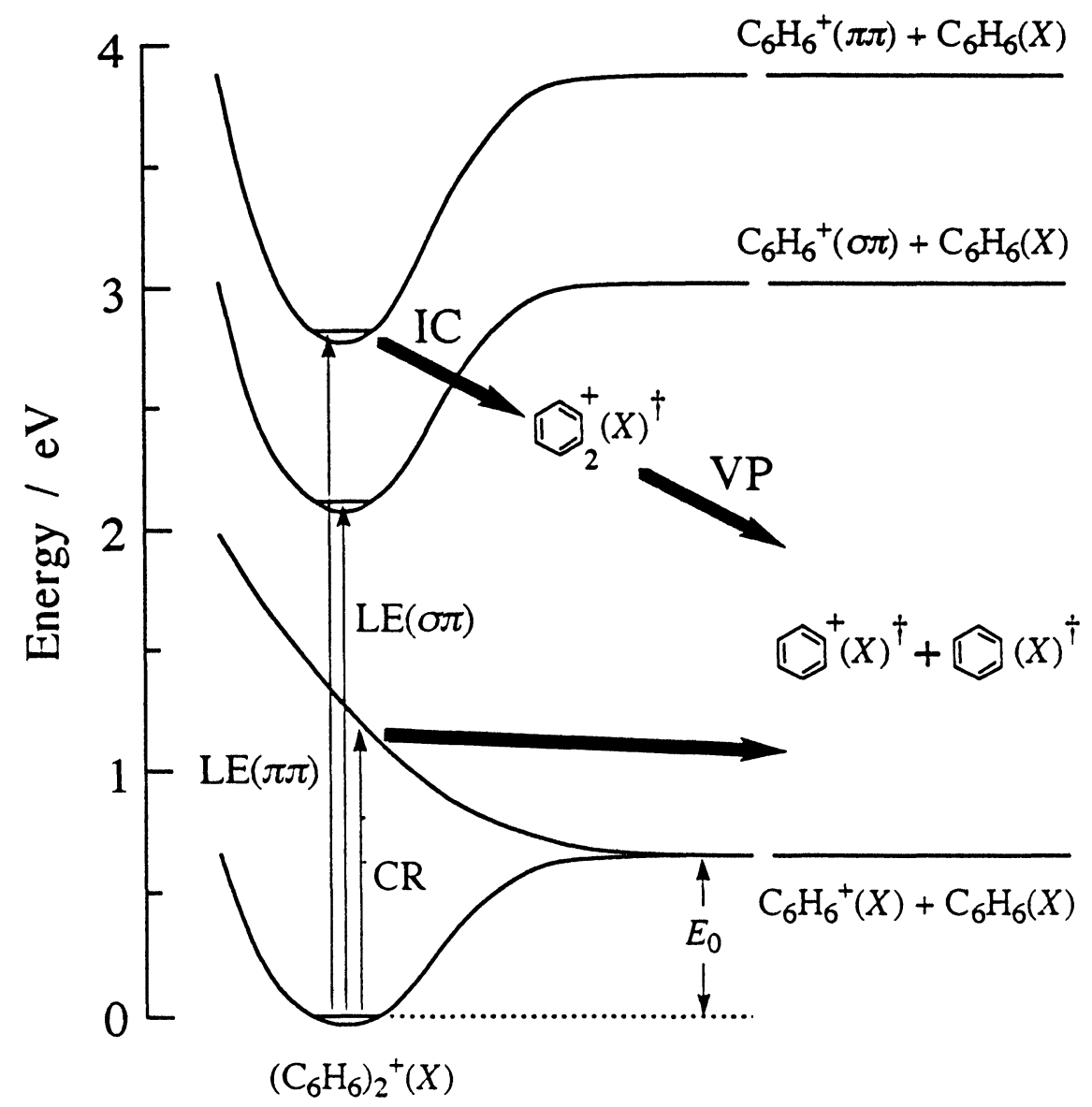

Figure 5 Schematic potential energy curves for $\left(\mathrm{C}_{6} \mathrm{H}_{6}\right)_{2}^{+}$as a function of intermolecular distance. Energy levels for $\left(\mathrm{C}_{6} \mathrm{H}_{6}\right)_{2}^{+}$are determined from the photodissociation spectrum. Energies for asymptotic monomer levels are taken from the literature. Mechanisms are indicated for the photodissociation following the $\mathrm{LE}(\pi \pi)$ and the CR excitation. $\dagger$ denotes vibrationally excited levels. IC: internal conversion; VP: vibrational predissociation; $\mathrm{E}_{0}$ : binding energy of $\left(\mathrm{C}_{6} \mathrm{H}_{6}\right)_{2}^{+}$

$\mathrm{C}_{6} \mathrm{H}_{6}^{+}(\pi \pi)+\mathrm{C}_{6} \mathrm{H}_{6}(X)$. Photon energies of $\approx 2.8 \mathrm{eV}(\approx 440 \mathrm{~nm})$ are not sufficient to reach the $\mathrm{C}_{6} \mathrm{H}_{6}^{+}(\pi \pi)+\mathrm{C}_{6} \mathrm{H}_{6}(\mathrm{X})$ or the $\mathrm{C}_{6} \mathrm{H}_{6}^{+}(\sigma \pi)+\mathrm{C}_{6} \mathrm{H}_{6}(\mathrm{X})$ dissociation asymptote. Thus both of the photoproducts, $\mathrm{C}_{6} \mathrm{H}_{6}^{+}$and $\mathrm{C}_{6} \mathrm{H}_{6}$, should be formed in their electronic ground states. The $\left(\mathrm{C}_{6} \mathrm{H}_{6}\right)_{2}^{+}$photoexcited to the bound excited state undergoes an internal conversion (IC) to vibrationally excited levels (labeled with $\dagger$ hereafter) of $\left(\mathrm{C}_{6} \mathrm{H}_{6}\right)_{2}^{+}(\mathrm{X})$. After the complete energy randomization, the $\left(\mathrm{C}_{6} \mathrm{H}_{6}\right)_{2}^{+}(\mathrm{X})^{\dagger}$ dissociates to $\mathrm{C}_{6} \mathrm{H}_{6}^{+}(\mathrm{X})^{\dagger}$ and $\mathrm{C}_{6} \mathrm{H}_{6}(\mathrm{X})^{\dagger}$ with large amount of internal energies as a result of vibrational predissociation (VP).

For the photodissociation in the CR band, the translational energy of the photofragments were measured to be at most $10 \%$ of the available energy. ${ }^{10}$ The only accessible 
state with photon energies of less than $2.1 \mathrm{eV}$ is the repulsive $\mathrm{CR}$ state correlated to $\mathrm{C}_{6} \mathrm{H}_{6}^{+}(\mathrm{X})+\mathrm{C}_{6} \mathrm{H}_{6}(\mathrm{X})$, because $\mathrm{C}_{6} \mathrm{H}_{6}^{+}$has no low lying excited electronic states below the $(\sigma \pi)$ state. The translational energy of the fragments is very small despite of the expected nature of the repulsive excited state. Small fraction of the available energy partitioned into the translation implies substantial excitation of internal motions of the fragments. Vibrational excitation of the photofragments is accompanied with the photodissociation at the CR band because of the change in equilibrium geometry of the constituent molecules upon the excitation and the dissociation. ${ }^{22}$ The two benzene moieties within $\left(\mathrm{C}_{6} \mathrm{H}_{6}\right)_{2}^{+}$in the ground state probably have an intermediate structure compared with those for separated $\mathrm{C}_{6} \mathrm{H}_{6}$ and $\mathrm{C}_{6} \mathrm{H}_{6}^{+}$, because the charge is shared with the two molecules. The electronic excitation of $\left(\mathrm{C}_{6} \mathrm{H}_{6}\right)_{2}^{+}$to a Franck-Condon region of the upper repulsive state could change the geometry of the two constituent molecules. The excitation produces a vibrationally excited pair of $\mathrm{C}_{6} \mathrm{H}_{6}^{+\dagger}+\mathrm{C}_{6} \mathrm{H}_{6}^{\dagger}$ because of large structural difference between the ground state $\mathrm{C}_{6} \mathrm{H}_{6}$ and $\mathrm{C}_{6} \mathrm{H}_{6}^{+}$.

\section{CONCLUSIONS}

We have employed photodissociation spectroscopy of size-selected cluster ions to obtain the electronic absorption spectrum of $\left(\mathrm{C}_{6} \mathrm{H}_{6}\right)_{2}^{+}$in the $400-1400 \mathrm{~nm}$ wavelength range. Two bands at 440 and $580 \mathrm{~nm}$ are assigned to the local excitation bands, in which the $\mathrm{C} \leftarrow \mathrm{X}(\pi \leftarrow \pi)$ and the $\mathrm{B} \leftarrow \mathrm{X}(\pi \leftarrow \sigma)$ transitions, respectively, are locally excited in a monomer cation unit of $\left(\mathrm{C}_{6} \mathrm{H}_{6}\right)_{2}^{+}$. The origin of the $B \leftarrow X$ transition is red-shifted by $\approx 1400 \mathrm{~cm}^{-1}$ from that of $\mathrm{C}_{6} \mathrm{H}_{6}^{+}$. This spectral shift can reasonably be explained by the stabilization of the $\pi$ orbitals of the cation due to the parallel stacking of the molecules. The most intense band at $920 \mathrm{~nm}$ is assigned to a charge resonance (CR) band. The existence of the intense $\mathrm{CR}$ absorption suggests that the charge is shared with the two molecules within $\left(\mathrm{C}_{6} \mathrm{H}_{6}\right)_{2}^{+}$and that the two moieties should be equivalent to each other. These observations support a parallel structure for $\left(\mathrm{C}_{6} \mathrm{H}_{6}\right)_{2}^{+}$rather than the T-shape structure. A relatively weak band at $1160 \mathrm{~nm}$ is assigned to another CR band. One can explain the feature of the appearance of the two CR bands by considering the MO configurations for displaced parallel structures with $\mathrm{C}_{2 \mathrm{~h}}$ symmetry. We have also demonstrated that the binding energies of aromatic dimer ions can be determined spectroscopically from the energies of the CR transitions.

\section{References}

1. Ion and Cluster Ion Spectroscopy and Structure, edited by J. P. Maier (Elsevier, Amsterdam, 1989).

2. T. Shida and W. H. Hamill. J. Chem. Phys., 44, 4372 (1966).

3. B. Badger and B. Broklehurst. Trans. Faraday Soc., 65, 2582 (1969).

4. J. H. Miller, L. Andrews, P. A. Lund and P. N. Schatz. J. Chem. Phys., 73, 4932 (1980).

5. T. Shida. Electronic Absorption Spectra of Radical Ions (Elsevier, Amsterdam, 1988), p. 12.

6. S. A. Milosevich, K. Saichek, L. Hinchey, W. B. England and P. Kovacic. J. Am. Chem. Soc., 105, 1088 (1983). 
7. K. Hiraoka, S. Fujimaki, K. Aruga and S. Yamabe. J. Chem. Phys., 95, 8413 (1991).

8. A. Hiraya and K. Shobatake. Chem. Phys. Lett., 178, 543 (1991).

9. H. Shinohara and N. Nishi. Chem. Phys., 129, 149 (1989).

10. K. Ohashi and N. Nishi. J. Chem. Phys., 98, 390 (1993).

11. L. Karlsson, L. Mattsson, R. Jadrny, T. Bergmark and K. Siegbahn. Physica Scripta, 14, 230 (1976).

12. K. Ohashi and N. Nishi. J. Chem. Phys., 95, 4002 (1991).

13. K. Walter, R. Weinkauf, U. Boesl and E. W. Schlag. Chem. Phys. Lett., 155, 8 (1989).

14. K. Ohashi and N. Nishi. J. Phys. Chem., 96, 2931 (1992).

15. A. Ishitani and S. Nagakura. Mol. Phys., 12, 1 (1967).

16. J. Tokuhiro and N. Mikami. Symposium on Molecular Science Kyoto (1992) Abstract p. 36 (in Japanese).

17. M. Fujii, K. Ohtsuka and M. Ito. Symposium on Chemical Reaction Sendai (1991) Abstract p. 67 (in Japanese).

18. B. Ernstberger, H. Krause, A. Kiermeier and H. J. Neusser. J. Chem. Phys., 92, 5285 (1990).

19. J. Tokuhiro, K. Ohtsuka, M. Fujii, N. Mikami and M. Ito. Symposium on Molecular Science Yokohama (1991) Abstract p. 240 (in Japanese).

20. T. Shibata, K. Ohashi, Y. Nakai and N. Nishi, to be published.

21. J. T. Snodgrass, R. C. Dunbar and M. T. Bowers. J. Phys. Chem., 94, 3648 (1990)

22. R. C. Mitchell and J. P. Simons. Discuss. Faraday Soc., 44, 208 (1967). 